Check for updates

Cite this: Phys. Chem. Chem. Phys. 2021, 23, 7724

Received 8th June 2020,

Accepted 12th August 2020

DOI: 10.1039/d0cp03079a

rsc.li/pccp

\section{Ethanol-ethylene conversion mechanism on hydrogen boride sheets probed by in situ infrared absorption spectroscopy $\dagger$}

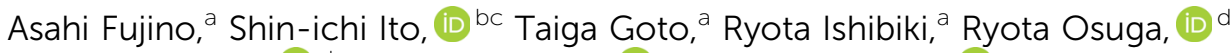 \\ Junko N. Kondo, (iD d Tadahiro Fujitani, (D) ce Junji Nakamura, (ID c Hideo Hosono (D) b \\ and Takahiro Kondo (iD *bc
}

\begin{abstract}
Two-dimensional hydrogen boride $(\mathrm{HB})$ sheets were recently demonstrated to act as a solid acid catalyst in their hydrogen-deficient state. However, both the active sites and the mechanism of the catalytic process require further elucidation. In this study, we analyzed the conversion of ethanol adsorbed on HB sheets under vacuum during heating using in situ Fourier transform infrared (FT-IR) absorption spectroscopy with isotope labelling. Up to $450 \mathrm{~K}$, the FT-IR peak associated with the $\mathrm{OH}$ group of the adsorbed ethanol molecule disappeared from the spectrum, which was attributed to a dehydration reaction with a hydrogen atom from the $\mathrm{HB}$ sheet, resulting in the formation of an ethyl species. At temperatures above $440 \mathrm{~K}$, the number of $\mathrm{BD}$ bonds markedly increased in $\mathrm{CD}_{3} \mathrm{CH}_{2} \mathrm{OH}$, compared to $\mathrm{CH}_{3} \mathrm{CD}_{2} \mathrm{OH}$; the temperature dependence of the formation rate of $\mathrm{BD}$ bonds was similar to that of the dehydration reaction rate of ethanol on $\mathrm{HB}$ sheets under steady-state conditions. The rate-determining step of the dehydration of ethanol on $\mathrm{HB}$ was thus ascribed to the dehydrogenation of the methyl group of the ethyl species on the HB sheets, followed by the immediate desorption of ethylene. These results show that the catalytic ethanol dehydration process on $\mathrm{HB}$ involves the hydrogen atoms of the HB sheets. The obtained mechanistic insights are expected to promote the practical application of HB sheets as catalysts.
\end{abstract}

\section{Introduction}

Two-dimensional (2D) materials offer considerable potential for application as catalysts or catalyst supports because of their unique properties such as large surface areas and novel electronic states. ${ }^{1,2}$ For example, graphene has shown superior properties as a support, ${ }^{3,4}$ while nitrogen-doped graphene exhibits excellent electrocatalytic properties in various reactions. ${ }^{5,6}$ 2D materials comprising boron are considered to possess unique properties owing to the large number of theoretically

\footnotetext{
${ }^{a}$ Graduate School of Pure and Applied Sciences, University of Tsukuba, 1-1-1, Tennodai, Tsukuba, Ibaraki, 305-8573, Japan

${ }^{b}$ Materials Research Center for Element Strategy, Tokyo Institute of Technology, Yokohama 226-8503, Japan. E-mail: takahiro@ims.tsukuba.ac.jp

${ }^{c}$ Department of Materials Science and Tsukuba Research Center for Energy Materials Science, Faculty of Pure and Applied Sciences, University of Tsukuba, Tsukuba 305-8573, Japan

${ }^{d}$ Institute of Innovative Research, Tokyo Institute of Technology, 4259 Nagatsuta, Yokohama, Kanagawa 226-8503, Japan

${ }^{e}$ Interdisciplinary Research Center, National Institute of Advanced Industrial Science and Technology, 1-1-1 Higashi, Tsukuba, Ibaraki 305-8565, Japan $\dagger$ Electronic supplementary information (ESI) available. See DOI: 10.1039/ d0cp03079a
}

predicted polymorphs. ${ }^{7,8}$ Various 2D boron-containing compounds, including boron chalcogenides, ${ }^{9}$ boron oxides, ${ }^{10,11}$ boron hydrides, ${ }^{12,13}$ and boron phosphides, ${ }^{14}$ have also been theoretically predicted to have a large number of polymorphs. Depending on the structure, the bonding strengths of the boron materials with gas molecules are expected to be different, thereby leading to a wide variety of catalytic properties for $2 \mathrm{D}$ boron-related materials. However, the experimental synthesis of $2 \mathrm{D}$ boron-related materials has rarely been reported. ${ }^{15,16}$

Hydrogen boride (HB) or hydrogenated borophene sheets are novel $2 \mathrm{D}$ boron materials that have been reported recently and are composed of two light elements, namely boron and hydrogen, in a $1: 1$ stoichiometric ratio. ${ }^{17} \mathrm{HB}$ sheets are terminated by protons on the negatively charged hexagonal boron sheets and they are known to exhibit versatile properties, such as a large $\mathrm{H}_{2}$ content (8.5 wt\%), semimetal electronic properties, ${ }^{18,19}$ metal ion reducibility, ${ }^{20}$ and a light-responsive hydrogen release function. ${ }^{21}$ Our recent study revealed that $\mathrm{HB}$ sheets in their hydrogen-deficient state $(\mathrm{H}: \mathrm{B}$ ratio of approximately $1: 2.5 \pm 0.5$ ) catalyze the conversion of ethanol to ethylene and water above $493 \mathrm{~K}$ with high selectivity independent of the contact time, and an apparent activation energy of 
$102.8 \pm 5.5 \mathrm{~kJ} \mathrm{~mol}^{-1} .^{22}$ The activation energy of this process is comparable to those reported for the catalytic dehydration of ethanol over $\mathrm{Al}_{2} \mathrm{O}_{3}\left(53-155 \mathrm{~kJ} \mathrm{~mol}^{-1}\right),{ }^{23,24}$ the Lewis acidic catalyst Zr-KIT-6 $\left(79 \mathrm{~kJ} \mathrm{~mol}^{-1}\right){ }^{25}$ silica-alumina $\left(125.5 \mathrm{~kJ} \mathrm{~mol}^{-1}\right){ }^{26}$ and the microporous Fe-ZSM-5 (137.7-271.1 $\left.\mathrm{kJ} \mathrm{mol}^{-1}\right) .{ }^{27}$ The formation rate of ethylene on the $\mathrm{HB}$ catalyst is lower than that offered by state-of-the-art catalysts, but is of the same order as that on the commercial SynDol $\left(\mathrm{Al}_{2} \mathrm{O}_{3}-\mathrm{MgO} / \mathrm{SiO}_{2}\right)$ catalyst. ${ }^{22}$ Therefore, $\mathrm{HB}$ sheets can be regarded as a solid-acid catalyst. However, the mechanism of $\mathrm{HB}$ catalysis has not yet been elucidated, and the active sites have not been identified. In this study, to gain insights into the $\mathrm{HB}$ catalysis of the ethanol conversion process, we conducted in situ Fourier transform infrared (FT-IR) absorption spectroscopy with isotope labelling, since the observation and analysis of the vibrational frequency shifts upon isotope labelling of the intermediate species by in situ FT-IR could lead to determination of the conversion mechanism of the molecules on solid surfaces. ${ }^{28}$ Overall, we investigate the interactions between the adsorbed ethanol and the HB sheets during heating under vacuum through in situ FT-IR spectroscopy and isotope labelling.

\section{Methods}

HB sheets were prepared using a previously reported ionexchange method. ${ }^{17-22}$ More specifically, $\mathrm{MgB}_{2}$ powder $(1.0 \mathrm{~g}$, 99\%, Rare Metallic Co., Ltd, Tokyo, Japan) in acetonitrile (300 mL, 99.5\%, Wako Pure Chemical Industries Ltd, Osaka, Japan) was added to a mixture of an ion-exchange resin $(60 \mathrm{~mL}$, Amberlite IR120B hydrogen, Organo Corp., Tokyo, Japan) and acetonitrile $(200 \mathrm{~mL})$ in a Schlenk flask under a nitrogen atmosphere. Water was carefully removed due to the facile hydrolysis of $\mathrm{MgB}_{2}{ }^{29}$ The resulting mixture was then stirred with a magnetic stirrer at $400 \mathrm{rpm}$ for $2-3 \mathrm{~d}$ at room temperature $(\sim 300 \mathrm{~K})$. After this time, the reaction mixture was allowed to settle for a sufficient time and the supernatant was collected and kept for $1 \mathrm{~d}$ at $255 \mathrm{~K}$ to physically separate the $\mathrm{B}(\mathrm{OH})_{3}$ byproduct. In samples containing unreacted materials, such as the oxides present in the starting materials, the reaction mixture was filtered through a 1.0 or $0.2 \mu \mathrm{m}$ pore filter (Omnipore Membrane Filters, Merck Millipore, Billerica, MA, USA) and the filtrate was kept for $1 \mathrm{~d}$ at $255 \mathrm{~K}$ to physically separate the $\mathrm{B}(\mathrm{OH})_{3}$ byproduct. Dried HB sheets were prepared by heating the resulting liquid at $343 \mathrm{~K}$, where the gas that evaporated during heating was pumped through a liquidnitrogen trap. We rigorously characterized the product using X-ray photoelectron spectroscopy (XPS, JPS 9010 TR, JEOL, Ltd, Tokyo, Japan) to confirm the absence of $\mathrm{Mg}$, the presence of negatively charged $\mathrm{B}$, and the absence of oxidized B (a survey $\mathrm{X}$-ray photoelectron spectrum of the HB sheets is shown in Fig. S1, ESI $\dagger){ }^{17-22}$

For in situ FT-IR spectroscopy analysis, we used a homemade vacuum system (Fig. S2, ESI $\dagger$ ) coupled with an FT-IR spectrometer (FT/IR-610, Jasco, Ltd, Tokyo, Japan) to observe the structural changes in the $\mathrm{HB}$ sheets during heating under vacuum $\left(1.0 \times 10^{-6}\right.$ Torr $)$ after exposure to ethanol vapor
( $\sim 44$ Torr in $123 \mathrm{cc}$ ) for $1 \mathrm{~h}$ at room temperature $(\sim 300 \mathrm{~K})$. The FT-IR measurements were conducted in transmission mode, with the sample mounted on $\mathrm{a} \mathrm{CaF}_{2}$ disk. Each spectrum was obtained by averaging 20 scans with a resolution of $4 \mathrm{~cm}^{-1}$. The IR absorbance $A$ is defined as $A=-\ln \left(T / T_{0}\right)$, where $T$ and $T_{0}$ are the transmitted intensities with and without the sample on the $\mathrm{CaF}_{2}$ disk, respectively. The heating rate was set as $7.2 \mathrm{~K} \mathrm{~min}^{-1}$; thus, the sample temperature increased by $2.4 \mathrm{~K}$ during the measurement time of $20 \mathrm{~s}$ for one spectrum (20 scans). The sample temperature was monitored using a K-type thermocouple close to the sample holder. To obtain details regarding the structural changes taking place in ethanol, the isotopes $\mathrm{CD}_{3} \mathrm{CH}_{2} \mathrm{OH}$ (ethanol-2,2,2- $d_{3}$, Santa Cruz Biotechnology, Inc., Dallas, TX, USA) and $\mathrm{CH}_{3} \mathrm{CD}_{2} \mathrm{OH}$ (ethanol-1,1- $d_{2}$, Santa Cruz Biotechnology, Inc., Dallas, TX, USA) were used in addition to $\mathrm{C}_{2} \mathrm{H}_{5} \mathrm{OH}$ (99.5\%, Wako Pure Chemical Industries Ltd, Osaka, Japan). To assign the FT-IR peaks, the vibrational modes of an isolated ethanol molecule were determined using density functional theory (DFT) calculations performed using Gaussian $16 .^{30}$ The functional and basis set used for the calculations were B3LYP and $6-31++\mathrm{g}(\mathrm{d}, \mathrm{p})$, respectively.

To determine the catalytic activity, gaseous ethanol was introduced onto the HB sheets using argon as a carrier gas under atmospheric pressure in a homemade fixed-bed flow reactor, as reported previously. ${ }^{22}$ The product gas was then analyzed downstream using a gas chromatograph (GC-8A, Shimadzu, Kyoto, Japan) with a thermal conductivity detector equipped with 5A molecular sieves and Porapak Q columns. The catalytic conversion was estimated from the total amount of hydrocarbon produced as follows: ethanol conversion (\%) = [(number of carbon atoms in detected hydrocarbon molecules) $\left(\mathrm{mol} \mathrm{min}^{-1}\right) /($ number of introduced ethanol molecules $\times 2$ ) $\left.\left(\mathrm{mol} \min ^{-1}\right)\right] \times 100$. The conversion estimated using this method has been confirmed to be similar to that estimated on the basis of the consumption of ethanol under our experimental conditions; ${ }^{22}$ therefore, the carbon accumulation on $\mathrm{HB}$ can be neglected. The $W / F$ conditions ( $\mathrm{g}$ min $\mathrm{mmol}^{-1}$ ), where $W$ is the weight of the catalyst $(\mathrm{g})$ and $F$ is the flow rate of $\mathrm{C}_{2} \mathrm{H}_{5} \mathrm{OH}$ $\left(\mathrm{mmol} \mathrm{min}^{-1}\right.$ ), were controlled by adjusting the $\mathrm{C}_{2} \mathrm{H}_{5} \mathrm{OH}$ flow rate and the sample weight. Under our experimental conditions $(W / F=4-30)$, the product exhibited no apparent $W / F$ dependence. $^{22}$

\section{Results and discussion}

Fig. 1 shows the FT-IR spectra of the HB sheets measured under vacuum before and after exposure to ethanol vapor or isotopelabelled ethanol vapor for $1 \mathrm{~h}$ at room temperature $(\sim 300 \mathrm{~K})$. In each case, new absorbance peaks originating from ethanol were observed after exposure to ethanol vapor. To assign the absorbance peaks, we compared the peak positions in the experimentally obtained spectra with those from the DFT calculations for isolated ethanol and the reported values for ethanol under various conditions ${ }^{31-40}$ as shown in Table 1 . In the case of $\mathrm{C}_{2} \mathrm{H}_{5} \mathrm{OH}$ (Fig. 1a), absorbance peaks corresponding to the $\mathrm{OH}$ group $\left(\nu_{\mathrm{OH}}\right), \mathrm{CH}_{3}$ group $\left(\nu_{\mathrm{CH}_{3}}\right)$, and $\mathrm{CH}_{2}$ group $\left(\nu_{\mathrm{CH}_{2}}\right)$ were 
(a)

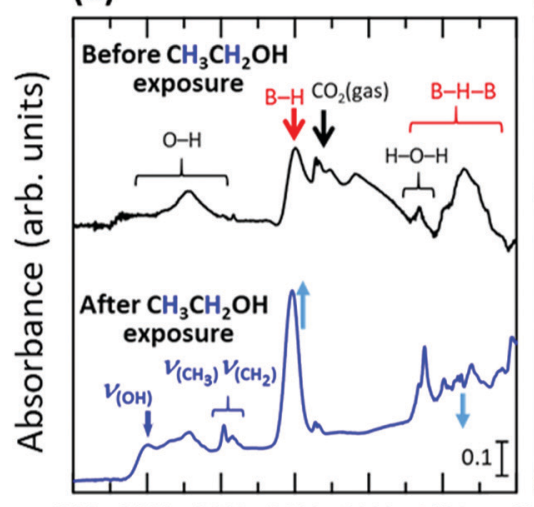

$4000 \quad 3500 \quad 3000 \quad 2500 \quad 2000 \quad 1500$ (b)

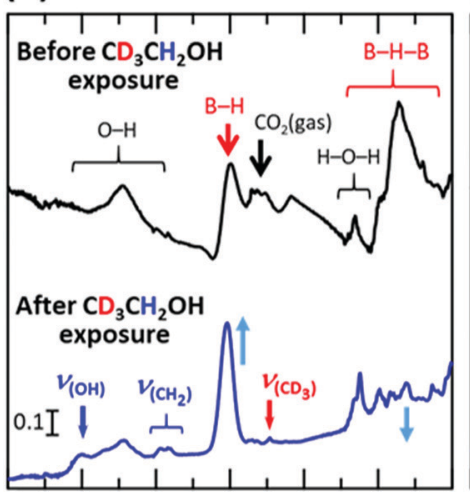

$40003500 \quad 3000 \quad 25002000 \quad 1500$

Wavenumber $\left(\mathrm{cm}^{-1}\right)$ (c)

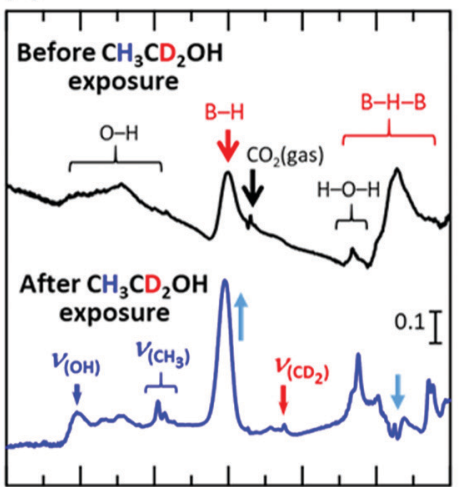

$4000 \quad 3500 \quad 3000 \quad 2500 \quad 2000 \quad 1500 \quad 1000$

Fig. $1 \mathrm{FT}$-IR spectra of the $\mathrm{HB}$ sheets obtained under vacuum before and after exposure to the vapour of ethanol or isotope-labelled ethanol for $1 \mathrm{~h}$ at room temperature ( $300 \mathrm{~K}$ ); (a) $\mathrm{CH}_{3} \mathrm{CH}_{2} \mathrm{OH}$, (b) $\mathrm{CD}_{3} \mathrm{CH}_{2} \mathrm{OH}$, and (c) $\mathrm{CH}_{3} \mathrm{CD}_{2} \mathrm{OH}$.

observed at 3492, 2980, and $2937 \mathrm{~cm}^{-1}$, respectively. An absorbance peak at $2230 \mathrm{~cm}^{-1}$ attributable to the $\mathrm{CD}_{3}$ group $\left(\nu_{\mathrm{CD}_{3}}\right)$ was only observed in the case of $\mathrm{CD}_{3} \mathrm{CH}_{2} \mathrm{OH}$ (Fig. 1b), and an absorbance peak at $2120 \mathrm{~cm}^{-1}$ attributable to the $\mathrm{CD}_{2}$ group $\left(\nu_{\mathrm{CD} 2}\right)$ was only observed in the case of $\mathrm{CH}_{3} \mathrm{CD}_{2} \mathrm{OH}$ (Fig. 1c). These results suggest that ethanol is adsorbed on the HB sheet at room temperature $(\sim 300 \mathrm{~K})$ under vacuum.

With the appearance of the ethanol-related absorbance peaks, the intensity of the broad absorbance peak at $\sim 1300 \mathrm{~cm}^{-1}$ decreased, while those of the peaks at 1650 and $2500 \mathrm{~cm}^{-1}$ increased. Furthermore, following exposure of the $\mathrm{HB}$ sheets to ethanol vapor, the peak at $2500 \mathrm{~cm}^{-1}$ shifted to $2520 \mathrm{~cm}^{-1}$ in each case (Fig. 1). These results indicate that the structure of the HB sheets changes upon the adsorption of ethanol. The absorbance peak at $1300 \mathrm{~cm}^{-1}$ can be assigned to the B-H-B vibrational mode, ${ }^{19}$ whereas the peak at $1650 \mathrm{~cm}^{-1}$ can be assigned to the bending vibration of $\mathrm{H}-\mathrm{O}-\mathrm{H}$ and/or the vibration of $\mathrm{B}-\mathrm{H}-\mathrm{B}$ bonds at sites with a large strain in the HB sheet, or at the edge of the HB sheet. ${ }^{17,19}$ The absorbance peak at $2500 \mathrm{~cm}^{-1}$ can be attributed to the B-H stretching vibration of isolated BH bonds in the $\mathrm{HB}$ sheet. ${ }^{17}$ These results suggest that the HB sheets may be distorted by the adsorption of ethanol, and some of the BH bonds in the BHB bonds may dissociate to form isolated $\mathrm{BH}$ bonds, as indicated by the increase in intensity and shift of the peak corresponding to isolated $\mathrm{BH}$ bonds following ethanol adsorption. The complicated profile in the $1000-1500 \mathrm{~cm}^{-1}$ region is caused by not only this change in the BHB bonds of the HB sheets, but also the appearance of absorbance peaks corresponding to the bending, rocking, twisting, scissoring, and wagging modes of the (normal and/or deuterated) methyl and methylene groups of the adsorbed ethanol and/or the stretching mode of $\mathrm{CO}$ in the adsorbed ethanol. ${ }^{28,31-40}$ Therefore, we mainly focused on the absorbance peaks outside this overlapped region, although some of the peaks were assigned, as shown in Fig. S4-S6 (ESI $\dagger$ ).

Fig. 2a shows the FT-IR spectra of the $\mathrm{HB}$ sheets with adsorbed $\mathrm{C}_{2} \mathrm{H}_{5} \mathrm{OH}$ (referred to as $\mathrm{C}_{2} \mathrm{H}_{5} \mathrm{OH} / \mathrm{HB}$ ) at 300 and $623 \mathrm{~K}$ under vacuum. As shown, the $\nu_{\mathrm{OH}}, \nu_{\mathrm{CH}_{3}}$, and $\nu_{\mathrm{CH}_{2}}$ peaks almost disappeared at $623 \mathrm{~K}$, while a decrease in peak intensity was observed for the peak of the B-H stretching vibrational mode at $2520 \mathrm{~cm}^{-1}$. In contrast, the absorbance at 1000$1500 \mathrm{~cm}^{-1}$ (the region including the B-H-B vibrational mode) increased with heating. This tendency, in which the peak intensity of B-H decreases while that of B-H-B increases (Fig. 2a), is opposite to that observed during the ethanol adsorption process (Fig. 1). These results indicate that when heated to $623 \mathrm{~K}$, ethanol is no longer adsorbed on the HB sheets and the original state of the HB sheets may somehow be recovered in terms of the $\mathrm{B}-\mathrm{H}-\mathrm{B}$ bonding configuration. Here, we note that the number of hydrogen atoms within the $\mathrm{HB}$ sheets should be lower at $623 \mathrm{~K}$ than at $300 \mathrm{~K}$ because hydrogen molecules are released during the decomposition of the $\mathrm{HB}$ sheets over the wide temperature range of $423-1473 \mathrm{~K}^{17,19,22}$ Thus, the decrease in peak intensity at $2520 \mathrm{~cm}^{-1}$ may also be caused by the partial decomposition of the HB sheets.

There are two possible reasons for the disappearance of ethanol from the HB sheets during heating, namely desorption and decomposition followed by desorption. To clarify the details of the process on $\mathrm{C}_{2} \mathrm{H}_{5} \mathrm{OH} / \mathrm{HB}$ during heating, in situ FT-IR spectra of $\mathrm{C}_{2} \mathrm{H}_{5} \mathrm{OH} / \mathrm{HB}$ were collected during heating under vacuum. Fig. $2 \mathrm{~b}$ shows the absorbance difference spectra during heating of the sample, in which the FT-IR spectrum at $300 \mathrm{~K}$ was subtracted from the spectrum at each temperature; a negative peak indicates a decrease in absorbance with heating whereas a positive peak indicates an increase (all spectra before subtraction are shown in Fig. S4a, ESI $\dagger$ ). Fig. 2c shows the magnified spectra in the $\nu_{\mathrm{OH}}, \nu_{\mathrm{CH}_{3}}, \nu_{\mathrm{CH}_{2}}$, and $\nu_{\mathrm{CH}_{2}}{ }^{\prime}$ regions (note that $\nu_{\mathrm{CH}_{2}}{ }^{\prime}$ is a new peak that appeared during heating). As shown by the intensity profile of each peak as a function of temperature in Fig. 2d, each peak clearly shows a different temperature dependence. More specifically, the $\nu_{\mathrm{OH}}$ peak intensity decreases with heating and disappears at $453 \mathrm{~K}$, whereas the $\nu_{\mathrm{CH}_{3}}$ peak intensity decreases slowly up to $523 \mathrm{~K}$. Meanwhile, the $\nu_{\mathrm{CH}_{2}}{ }^{\prime}$ peak intensity increases initially from 400 to $453 \mathrm{~K}$ at the expense of the $\nu_{\mathrm{CH}_{2}}$ peak intensity and then decreases 


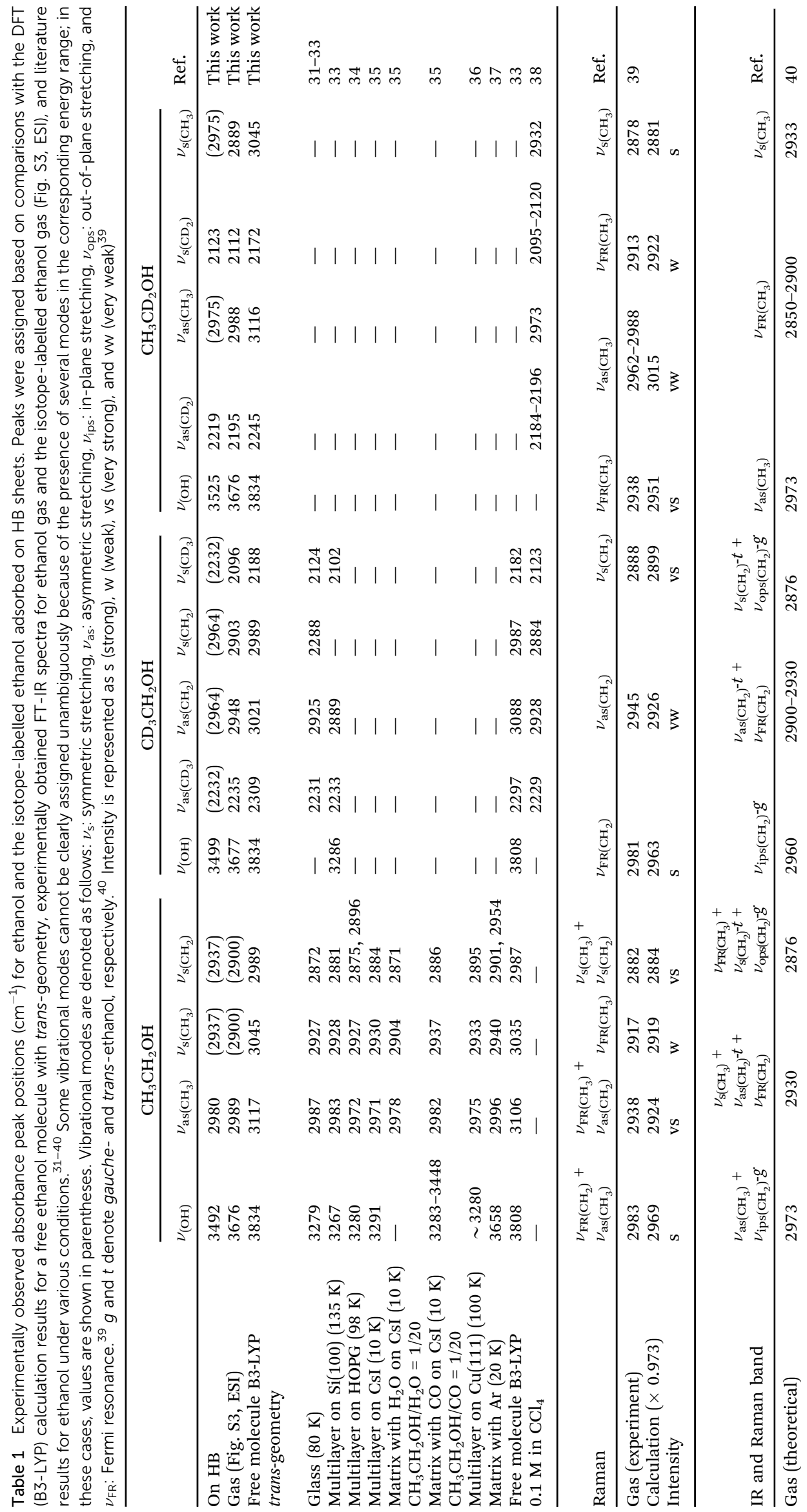


(a)

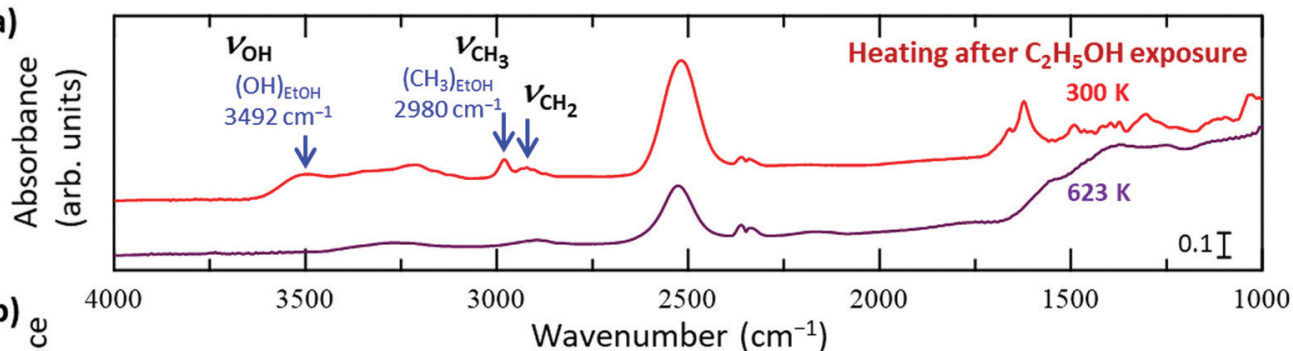

(b)

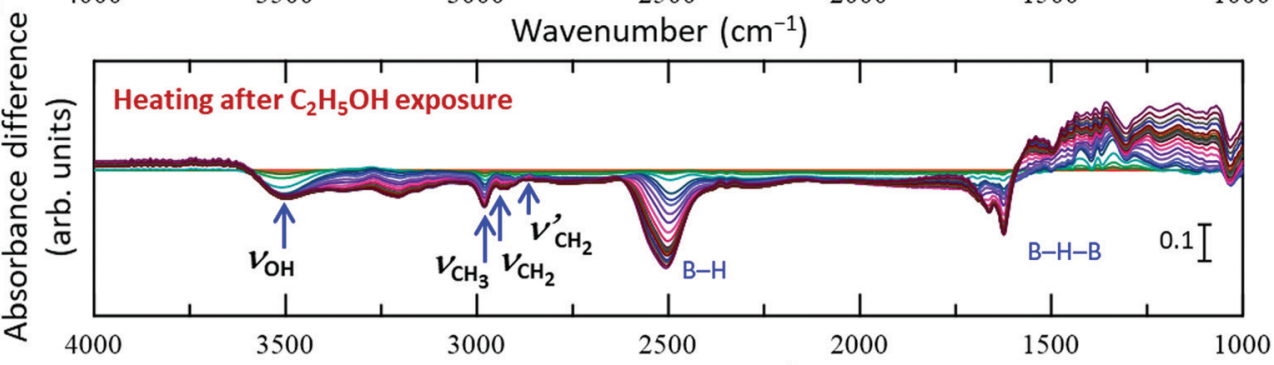

(c)

Wavenumber $\left(\mathrm{cm}^{-1}\right)$

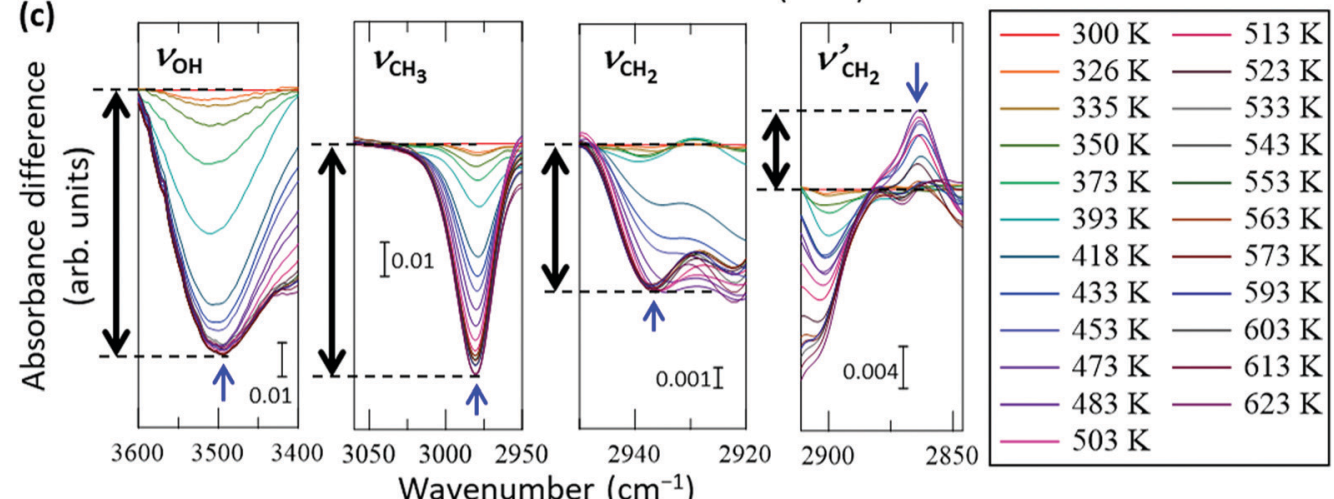

(d)

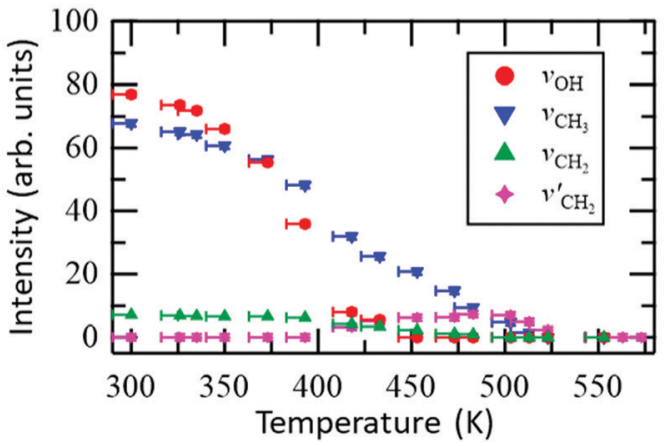

(e)

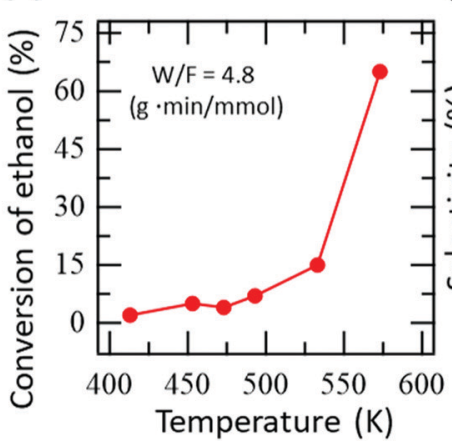

(f) $573 \mathrm{~K}$

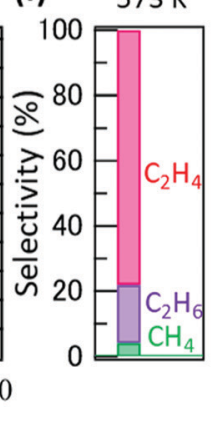

Fig. 2 In situ FT-IR analysis results of the $\mathrm{HB}$ sheets with adsorbed $\mathrm{C}_{2} \mathrm{H}_{5} \mathrm{OH}\left(\mathrm{C}_{2} \mathrm{H}_{5} \mathrm{OH} / \mathrm{HB}\right)$ during heating under vacuum. (a) FT-IR spectra of $\mathrm{C}_{2} \mathrm{H}_{5} \mathrm{OH} /$ $\mathrm{HB}$ at 300 and $623 \mathrm{~K}$ under vacuum. (b) Absorbance difference spectra during the heating of $\mathrm{C}_{2} \mathrm{H}_{5} \mathrm{OH} / \mathrm{HB}$; the FT-IR spectrum at $300 \mathrm{~K}$ was subtracted from the spectrum at each temperature (all spectra before subtraction are shown in Fig. S4a, ESI + ). (c) Magnified spectra in the $\mathrm{OH}$ group $\left(\nu_{\mathrm{OH}}\right)$, $\mathrm{CH}_{3}$ group $\left(\nu_{\mathrm{CH}_{3}}\right)$, and $\mathrm{CH}_{2}$ group $\left(\nu_{\mathrm{CH}_{2}}\right.$ and $\left.\nu_{\mathrm{CH}_{2}}{ }^{\prime}\right)$ regions (note that $\nu_{\mathrm{CH}_{2}}{ }^{\prime}$ corresponds to a new peak that appeared during heating). (d) Intensity change of each peak in (c) as a function of temperature; the intensity of the final state is set as zero for each case. (e) Conversion of the ethanol reforming reaction investigated using a fixed-bed flow reactor at $W / F=4.8 \mathrm{~g} \mathrm{~min} \mathrm{mmol}^{-1}$ in the presence of HB sheets without heating pre-treatment. The measurements were conducted sequentially while increasing the temperature from 413 to $575 \mathrm{~K}$. (f) Product selectivity at $573 \mathrm{~K}$ for the results in (e).

from $503 \mathrm{~K}$ to $553 \mathrm{~K}$. These results indicate that the disappearance of ethanol is not due to a simple desorption process but instead due to the conversion of ethanol to other species. Importantly, the results presented in Fig. 2a-d clearly show that the $\mathrm{OH}$ group of ethanol disappears first. This observation is consistent with previously reported results for the catalytic process under steadystate conditions, where the HB sheets in the hydrogen-deficient state catalyze the conversion of ethanol to ethylene and water through a dehydration reaction $\left(\mathrm{C}_{2} \mathrm{H}_{5} \mathrm{OH} \rightarrow \mathrm{C}_{2} \mathrm{H}_{4}+\mathrm{H}_{2} \mathrm{O}\right)$ at temperatures above $493 \mathrm{~K} .{ }^{22}$ Fig. 2e shows the conversion of the ethanol reforming reaction in the presence of HB sheets without heating pre-treatment, as measured using a fixed-bed flow reactor

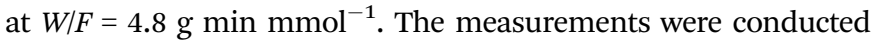
sequentially while increasing the temperature from 413 to $575 \mathrm{~K}$. 
The product selectivity at $573 \mathrm{~K}$ is shown in Fig. 2f. Although these measurement conditions differ from those used for the FT-IR measurements of $\mathrm{C}_{2} \mathrm{H}_{5} \mathrm{OH} / \mathrm{HB}$ under vacuum, the results are consistent in terms of the disappearance of the $\mathrm{OH}$ group of ethanol on the HB sheets. Due to the fact that the $\nu_{\mathrm{CH}_{3}}$ and $\nu_{\mathrm{CH}_{2}}{ }^{\prime}$ peaks are still observed in the FT-IR spectra after the disappearance of the $\nu_{\mathrm{OH}}$ peak (Fig. $2 \mathrm{~b}-\mathrm{d}$ ), the intermediate decomposition product of ethanol likely remains on the $\mathrm{HB}$ sheets at $453 \mathrm{~K}$.

There are two possible intermediate decomposition products of $\mathrm{C}_{2} \mathrm{H}_{5} \mathrm{OH}$ that may generate the $\nu_{\mathrm{CH}_{3}}$ and $\nu_{\mathrm{CH}_{2}}{ }^{\prime}$ peaks even after the disappearance of $\nu_{\mathrm{OH}}$ : (i) ethyl species $\left(\mathrm{CH}_{3} \mathrm{CH}_{2}-\right)$ and (ii) ethoxy species $\left(\mathrm{CH}_{3} \mathrm{CH}_{2} \mathrm{O}-\right)$. Herein, it can be interpreted that the intermediate decomposition product is an ethyl species rather than an ethoxy species, because the $\nu_{\mathrm{OH}}$ peak did not reappear upon heating after its complete disappearance at $453 \mathrm{~K}$ (Fig. 2). Importantly, for the dehydration reaction $\left(\mathrm{C}_{2} \mathrm{H}_{5} \mathrm{OH} \rightarrow\right.$ $\mathrm{C}_{2} \mathrm{H}_{4}+\mathrm{H}_{2} \mathrm{O}$ ) to occur continuously on the $\mathrm{HB}$ sheets as a catalytic conversion, as shown in Fig. $2 \mathrm{e}$ and as previously reported, ${ }^{22}$ the $\mathrm{OH}$ group must be formed from the ethoxy species or from the decomposed product of the ethoxy species as an intermediate to form $\mathrm{H}_{2} \mathrm{O}$ on $\mathrm{HB}$ sheets. Furthermore, a continuous decrease in the peak intensities at $1070-1150 \mathrm{~cm}^{-1}$ was observed up to $453 \mathrm{~K}$, ultimately leading to the saturation of the peak change (Fig. S4b, $\mathrm{ESI} \dagger$ ). This peak can be assigned to the CO stretching vibrational mode of ethanol $\left(\nu_{\mathrm{CO}}\right){ }^{31-37}$ If the ethoxy species is formed, the $\nu_{\mathrm{CO}}$ peak should be observed at a similar position even at temperatures above $453 \mathrm{~K}$, and its intensity should decrease with temperature. Although $\nu_{\mathrm{CO}}$ can be interpreted to be present even above $453 \mathrm{~K}$, the intensity decrease is saturated between 453 and $623 \mathrm{~K}$, as can be inferred from Fig. S4b (ESI $\dagger$ ). Therefore, the ethoxy species may not be involved in the reaction, despite possibly being formed on the surface. Upon analysis, the ethanol isotope $\left(\mathrm{CD}_{3} \mathrm{CH}_{2} \mathrm{OH}\right.$ and $\left.\mathrm{CH}_{3} \mathrm{CD}_{2} \mathrm{OH}\right)$ results fail to explain this phenomenon (Fig. S5 and S6, ESI $\dagger$ ). To sufficiently elucidate the possibility of ethoxy formation, experiments using isotopelabelled ethanol of $\mathrm{C}_{2} \mathrm{H}_{5} \mathrm{OD}$ are required, which will be carried out in our future work. However, the absence of the $\nu_{\mathrm{OH}}$ peak at temperatures exceeding $453 \mathrm{~K}$ suggests that the intermediate decomposition product of ethanol present at temperatures above $453 \mathrm{~K}$ is not the ethoxy species but the ethyl species.

To clarify the conversion process of ethanol adsorbed on the HB sheets more in detail, we conducted the same FT-IR experiments with isotope-labelled ethanol $\left(\mathrm{CD}_{3} \mathrm{CH}_{2} \mathrm{OH}\right.$ and $\mathrm{CH}_{3} \mathrm{CD}_{2} \mathrm{OH}$ ), as shown in Fig. 3 and 4, respectively (all the original spectra before subtraction are shown in Fig. S5 and S6, ESI $\dagger$ ). For both isotopes, the observed trends were the same as those for $\mathrm{C}_{2} \mathrm{H}_{5} \mathrm{OH}$ (Fig. 2), i.e., the $\nu_{\mathrm{OH}}$ peak intensity decreased with heating and disappeared at $\sim 440 \mathrm{~K}$, whereas the $\nu_{\mathrm{CD} 3}$, $\nu_{\mathrm{CH} 2}, \nu_{\mathrm{CD} 2}$, and $\nu_{\mathrm{CH} 3}$ peak intensities decreased slowly up to $\sim 550 \mathrm{~K}$. Interestingly, in the case of $\mathrm{CD}_{3} \mathrm{CH}_{2} \mathrm{OH}$, an absorbance peak attributable to the B-D stretching vibration $\left(\nu_{\mathrm{BD}}\right)$ appeared at $1895 \mathrm{~cm}^{-1}$ at $\sim 440 \mathrm{~K}$ (together with the disappearance of $\nu_{\mathrm{OH}}$ ), and the absorbance intensity increased with temperature (Fig. 3c and e). This observation indicates that the $\mathrm{CD}_{3}$ group of $\mathrm{CD}_{3} \mathrm{CH}_{2} \mathrm{OH}$ is decomposed on $\mathrm{HB}$ to form a BD bond after the disappearance of the $\mathrm{OH}$ group. In other words, the hydrogen deficient HB sheets may undergo a dehydrogenation reaction with the deuterium atom from the $\mathrm{CD}_{3}$ group of the $\mathrm{CD}_{3} \mathrm{CH}_{2}$ species on $\mathrm{HB}$. The product of this reaction, $\mathrm{CD}_{2} \mathrm{CH}_{2}$, might subsequently be desorbed into the gas phase because both $\nu_{\mathrm{CH} 2}$ and $\nu_{\mathrm{CD} 3}$ intensities decrease continuously upon heating to $550 \mathrm{~K}$ (Fig. 3a-d). Similarly, in the case of $\mathrm{CH}_{3} \mathrm{CD}_{2} \mathrm{OH}$, an absorbance peak appeared at $1895 \mathrm{~cm}^{-1}$; however, the peak intensity was considerably lower than that in the case of $\mathrm{CD}_{3} \mathrm{CH}_{2} \mathrm{OH}$ (Fig. 3e and 4e). More specifically, the maximum intensity ratios for $\nu_{\mathrm{OH}(\mathrm{MAX})} / \nu_{\mathrm{BD}(\mathrm{MAX})}$ were 14.0 for $\mathrm{CD}_{3} \mathrm{CH}_{2} \mathrm{OH}$ and 3.4 for $\mathrm{CH}_{3} \mathrm{CD}_{2} \mathrm{OH}$. These results indicate that hydrogen abstraction during the dehydrogenation reaction occurs preferentially from the methyl group rather than the methylene group of the decomposed ethanol.

Of the several possible dehydration mechanisms available to ethanol on the solid surface, ${ }^{28,41-46}$ two involve dehydrogenation of the intermediate species by the atoms of the solid surface. More specifically, in the case of $\mathrm{CH}_{3} \mathrm{CD}_{2} \mathrm{OH}$, dehydrogenation may occur after the hydration reaction via the formation of an ethyl species $\left(\mathrm{CH}_{3} \mathrm{CD}_{2}\right)$ bonded to boron as an intermediate $\left(\mathrm{CH}_{3} \mathrm{CD}_{2}-\mathrm{B}_{\text {(in } \mathrm{HB})}\right)$, followed by dehydrogenation at the $\mathrm{CH}_{3}$ group with the concerted elimination of $\mathrm{C}-\mathrm{B}$ and $\mathrm{C}-\mathrm{H}$ bonds; in this case, the $\mathrm{BH}$ bond is expected to form without $\mathrm{BD}$ bond formation on the $\mathrm{HB}$ sheets (thus $\mathrm{BD} / \mathrm{BH}=0$ ). Alternatively, it may occur via the formation of a free carbenium ion (carbocation) as a transition state, with or without an intermediate state, $\mathrm{CH}_{3} \mathrm{CD}_{2}-\mathrm{B}_{\text {(in HB) }}$, followed by dehydrogenation; in this case, the carbocation formed is converted to a more stable symmetric species, in which the two $\mathrm{C}$ atoms are equivalent. ${ }^{28}$ Thus, all $\mathrm{H}$ or $\mathrm{D}$ atoms can be considered to have the same probability of remaining in the $\mathrm{HB}$ sheets when evolving into ethylene. The expected $\mathrm{BD} / \mathrm{BH}$ ratio in the product sites for this mechanism is therefore 0.67. Using the experimentally obtained maximum intensity ratios for $\nu_{\mathrm{OH}(\mathrm{MAX})} /$ $\nu_{\mathrm{BD}(\mathrm{MAX})}$ (14.0 for $\mathrm{CD}_{3} \mathrm{CH}_{2} \mathrm{OH}$ and 3.4 for $\mathrm{CH}_{3} \mathrm{CD}_{2} \mathrm{OH}$ ), the corresponding $\mathrm{BD} / \mathrm{BH}$ ratio can be evaluated as $3.4 / 14=0.24$, which is slightly larger than 0 but smaller than 0.67 . If we consider the possible isotope exchange reaction for $\mathrm{CH}_{3} \mathrm{CD}_{2} \mathrm{OH}$ (for example, the isotope exchange reaction at the transition state from ethyl species to ethylene), the finite value of the ratio is reasonable; thus, dehydrogenation is suggested to occur at the methyl group rather than the methylene group of the ethyl species, without forming a carbocation. This is consistent with the fact that the positions of the $\nu_{\mathrm{CH} 3}$ or $\nu_{\mathrm{CD} 3}$ peaks do not shift (Fig. 2c, 3c and 4c), indicating that the bonding configuration of the methyl group is maintained as a part of the ethyl species until the methyl group is cleaved by the dehydrogenation reaction (concerted elimination), rather than the formation of another intermediate by sequential complete bond cleavages such as $\mathrm{C}-\mathrm{B}$ bond cleavage followed by $\mathrm{C}-\mathrm{H}$ bond cleavage. Concomitantly, the absorbance peak at $2864 \mathrm{~cm}^{-1}\left(\nu_{\mathrm{CH} 2}{ }^{\prime}\right)$ observed in Fig. 2c can be assigned to the $\mathrm{CH}_{2}$ group in the ethyl species $\left(\mathrm{CH}_{3} \mathrm{CH}_{2}-\mathrm{B}_{(\mathrm{in} \mathrm{HB})}\right)$ generated by the decomposition of $\mathrm{CH}_{3} \mathrm{CH}_{2} \mathrm{OH}$ via dehydration on the $\mathrm{HB}$ sheets. As such, the $\nu_{\mathrm{CH} 2}{ }^{\prime}$ peak intensity initially increases as the $\nu_{\mathrm{OH}}$ intensity decreases, and subsequently, the $\nu_{\mathrm{CH} 2}{ }^{\prime}$ intensity begins to 

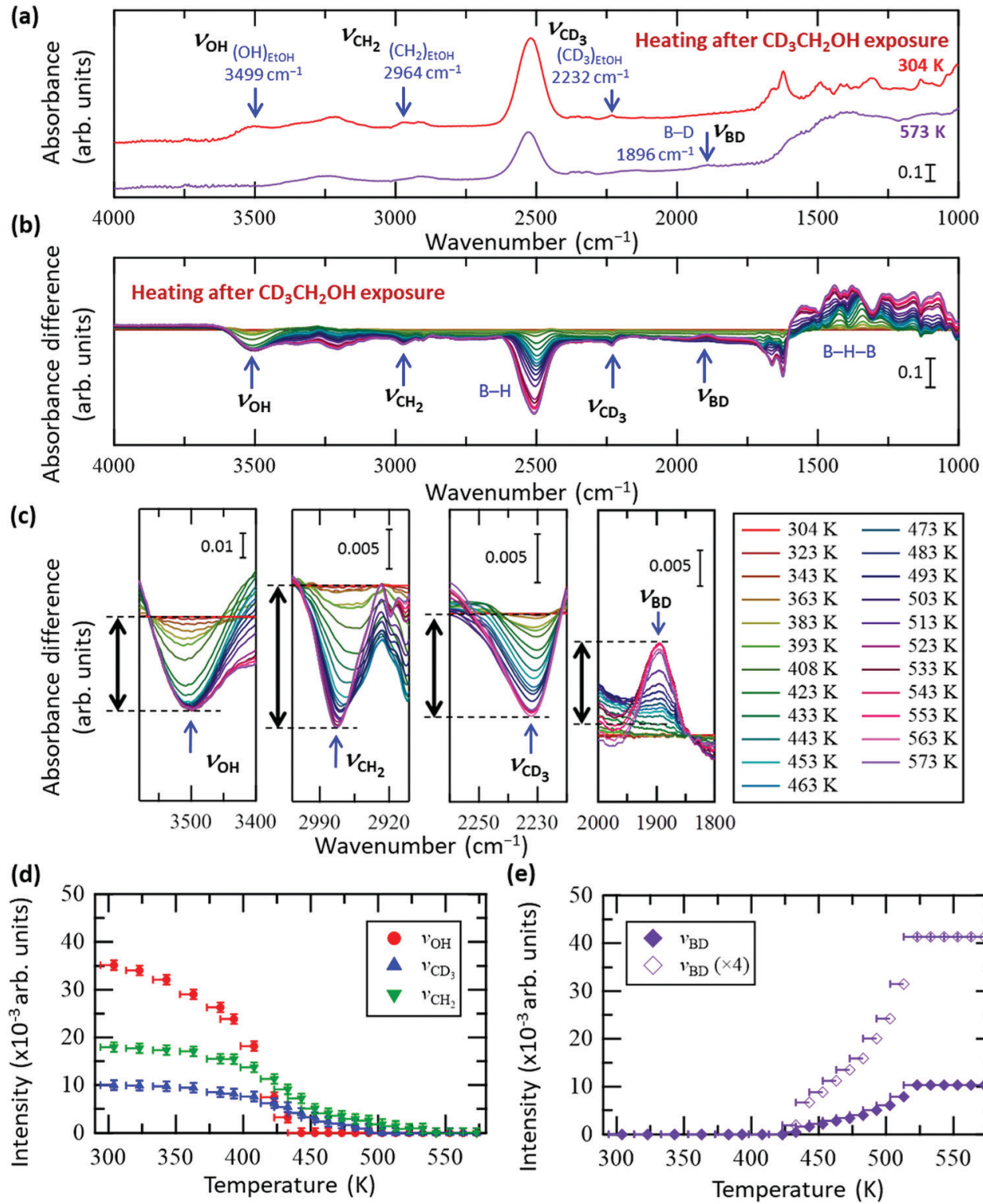

(e)

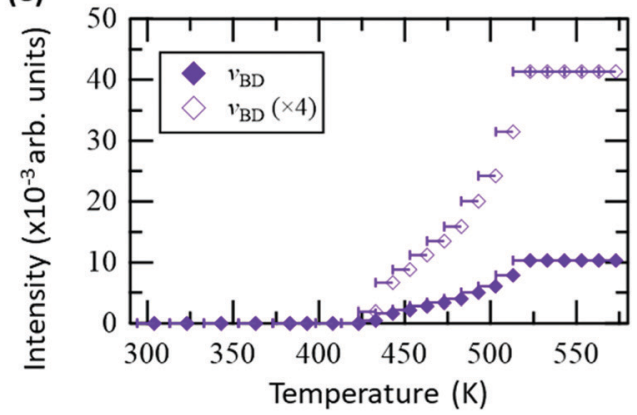

Fig. 3 In situ FT-IR analysis results of the $\mathrm{HB}$ sheets with adsorbed $\mathrm{CD}_{3} \mathrm{CH}_{2} \mathrm{OH}\left(\mathrm{CD}_{3} \mathrm{CH}_{2} \mathrm{OH} / \mathrm{HB}\right)$ during heating under vacuum. (a) FT-IR spectra of $\mathrm{CD}_{3} \mathrm{CH}_{2} \mathrm{OH} / \mathrm{HB}$ at 304 and $573 \mathrm{~K}$ under vacuum. (b) Absorbance difference spectra during heating of $\mathrm{CD}_{3} \mathrm{CH}_{2} \mathrm{OH} / \mathrm{HB}$; the FT-IR spectrum at $304 \mathrm{~K}$ was subtracted from the spectrum at each temperature (all spectra before subtraction are shown in Fig. S5a, ESI $\dagger$ ). (c) Magnified spectra in the OH group $(\nu \mathrm{OH}$ ), $\mathrm{CH}_{2}$ group $\left(\nu_{\mathrm{CH}_{2}}\right), C D_{3}$ group $\left(\nu_{\mathrm{CD}_{3}}\right)$, and BD group $\left(\nu_{\mathrm{BD}}\right)$ regions. (d and e) Intensity change of each peak in (c) as a function of temperature. The intensity of the final state is set to zero in (d), whereas the intensity of the initial state is set to zero in (e).

decrease together with the $\nu_{\mathrm{CH} 3}$ intensity (Fig. 2d) due to the dehydrogenation of the ethyl species.

Fig. 5 shows the Arrhenius plot of the reaction rate $k$ (left axis), where $k=\left(\mathrm{C}_{2} \mathrm{H}_{5} \mathrm{OH}\right.$ conversion [\%] $) / 100 \times\left(\mathrm{C}_{2} \mathrm{H}_{5} \mathrm{OH}\right.$ flux $\left.\left[\mathrm{mol} \mathrm{s}^{-1}\right]\right) /(\mathrm{HB}$ amount [mol] $)$ was estimated from the results shown in Fig. 2e. The results for $\ln \left(\Delta A_{\mathrm{BD}} / \Delta t\right)$ are presented on the right axis to evaluate the formation rate of the $\mathrm{BD}$ bond, where $\Delta A_{\mathrm{BD}} / \Delta t$ is the time derivative of the $\nu_{\mathrm{BD}}$ intensity $\left(A_{\mathrm{BD}}\right)$ for the data shown in Fig. 3e. It should be noted that while the values on the vertical axes are different, the width is the same to facilitate comparison of the slopes. Above $480 \mathrm{~K}$, the slopes are similar between $\ln k$ and $\ln \left(\Delta A_{\mathrm{BD}} / \Delta t\right)$, indicating that the $\mathrm{BD}$ bond formation rate determines the reaction rate of the ethanolethylene conversion on the HB sheets under our experimental conditions, i.e., the rate-determining step is the dehydrogenation of the intermediate ethyl species $\left(\mathrm{CH}_{3} \mathrm{CH}_{2}-\mathrm{B}_{(\mathrm{in} \mathrm{HB})}\right)$. It is known that the activation energy for the bond cleavage of $\mathrm{CD}$ is higher than that for $\mathrm{CH}$ due to the zero-point energy difference; the zeropoint energy of $\mathrm{CH}$ is approximately 1.36 times higher than that of $\mathrm{CD}$, based on the vibrational energy of a simple classical harmonic oscillator with the same spring constant. The similar slopes of $\ln k$ (estimated from $\mathrm{CH}_{3} \mathrm{CH}_{2} \mathrm{OH}$ ) and $\ln \left(\Delta A_{\mathrm{BD}} / \Delta t\right.$ ) (estimated for $\mathrm{CD}_{3} \mathrm{CH}_{2} \mathrm{OH}$ ) in Fig. 5 indicate similar activation energies, which is consistent with the concerted mechanism 

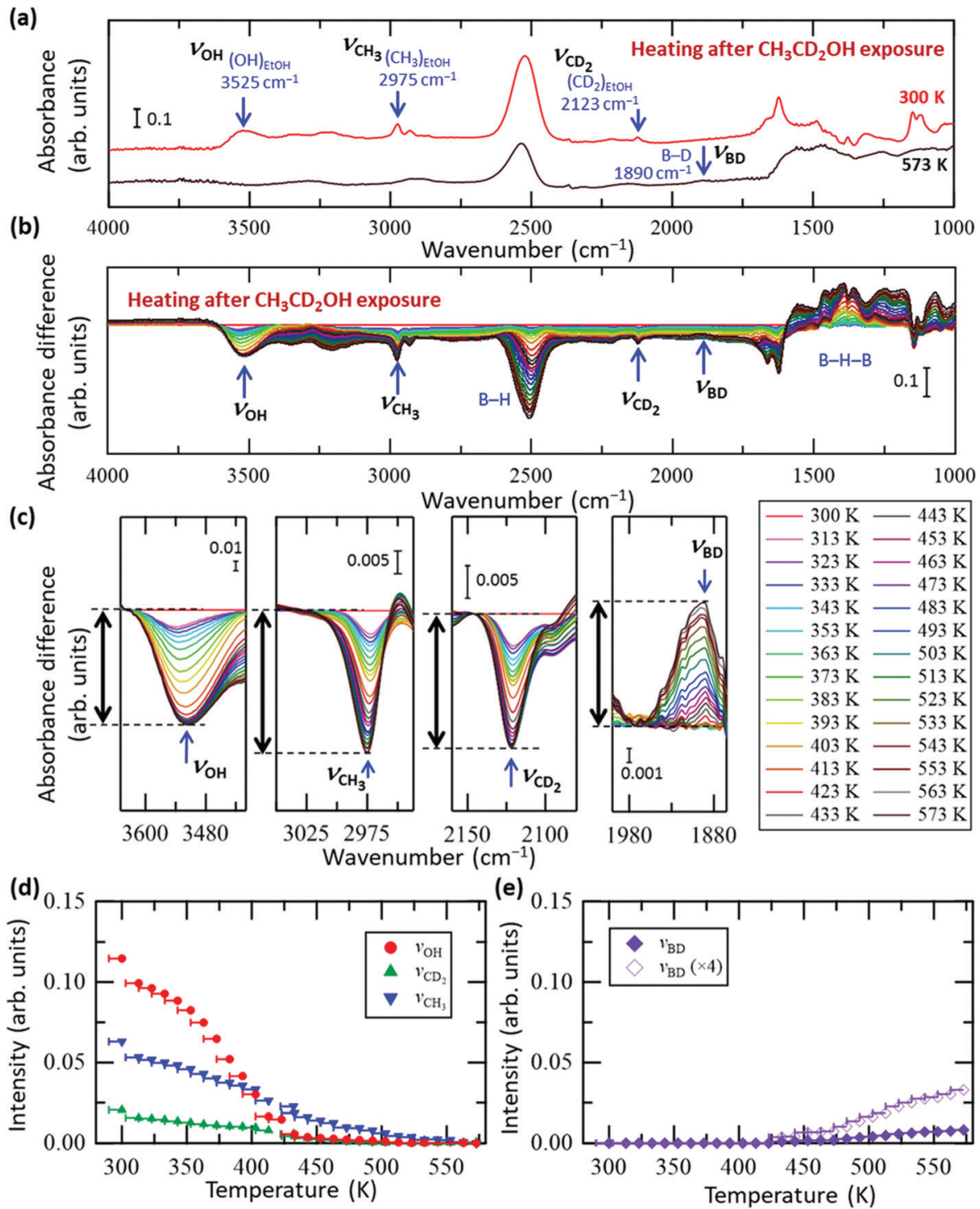

Fig. 4 In situ FT-IR analysis results of the $\mathrm{HB}$ sheets with adsorbed $\mathrm{CH}_{3} \mathrm{CD}_{2} \mathrm{OH}\left(\mathrm{CH}_{3} \mathrm{CD}_{2} \mathrm{OH} / \mathrm{HB}\right)$ during heating under vacuum. (a) $\mathrm{FT}$-IR spectra of $\mathrm{CH}_{3} \mathrm{CD}_{2} \mathrm{OH} / \mathrm{HB}$ at 300 and $573 \mathrm{~K}$ under vacuum. (b) Absorbance difference spectra during the heating of $\mathrm{CH}_{3} \mathrm{CD}_{2} \mathrm{OH} / \mathrm{HB}$; the $\mathrm{FT}$-IR spectrum at $300 \mathrm{~K}$ was subtracted from the spectrum at each temperature (all spectra before subtraction are shown in Fig. S6a, ESI $\dagger$ ). (c) Magnified spectra in the OH group $\left(\nu_{\mathrm{OH}}\right), \mathrm{CH}_{3}$ group $\left(\nu_{\mathrm{CH}_{3}}\right), \mathrm{CD}_{2}$ group $\left(\nu_{\mathrm{CD}_{2}}\right)$, and $\mathrm{BD}$ group $\left(\nu_{\mathrm{BD}}\right)$ regions. (d and e) Intensity change of each peak in (c) as a function of temperature. The intensity of the final state is set to zero in (d), whereas the intensity of the initial state is set to zero in (e).

(discussed in the previous paragraph), where the cleavage of both the $\mathrm{C}-\mathrm{B}$ and $\mathrm{C}-\mathrm{H}$ or $\mathrm{C}-\mathrm{D}$ bonds proceeds simultaneously. Thus, the contribution of the $\mathrm{C}-\mathrm{H}$ or $\mathrm{C}-\mathrm{D}$ bond in the apparent activation energy is less for the concerted mechanism compared to that for the complete cleavage mechanism. As shown in Fig. 5, the slope of $\ln k$ is slightly less steep than those reported for the HB samples with heating pre-treatment at $573 \mathrm{~K}$ under a flow of Ar for $1 \mathrm{~h}$ (left axis) ${ }^{22}$ and a clear flat region can be seen below $480 \mathrm{~K}$. These results indicate that the catalytic activity changes with heating due to the inevitable hydrogen release from $\mathrm{HB}$ sheets in the case of the sample without heating pre-treatment. ${ }^{22}$ However the differences in slopes are small at higher temperatures (above $480 \mathrm{~K}$ ), suggesting that the rate-determining step of the ethanol-ethylene conversion is also the dehydrogenation of the intermediate ethyl group $\left(\mathrm{CH}_{3} \mathrm{CH}_{2}-\mathrm{B}_{(\mathrm{in} \mathrm{HB})}\right)$ for the HB sheets with heating pre-treatment. Since the $\nu_{\mathrm{BD}}$ intensity is constant above $523 \mathrm{~K}$ (Fig. 3e), it is assumed that the formed BD species is not decomposed and released as $\mathrm{HD}$ or $\mathrm{D}_{2}$ but stays on the $\mathrm{HB}$ sheets at least at $523 \mathrm{~K}$ under our experimental conditions, i.e., the observed slope for $\ln \left(\Delta A_{\mathrm{BD}} / \Delta t\right)$ may not include the contribution of their decomposition.

Finally, we proposed a mechanism for the ethanol dehydration reaction on HB sheets based on the in situ FT-IR analysis, as shown in Fig. 6 and the following chemical equations, using isotope-labelled $\mathrm{CD}_{3} \mathrm{CH}_{2} \mathrm{OH}$ :

$\mathrm{CD}_{3} \mathrm{CH}_{2} \mathrm{OH}_{(\mathrm{g})}+\mathrm{BHB}_{(\text {in HB })} \rightarrow \mathrm{CD}_{3} \mathrm{CH}_{2} \mathrm{OH}_{(\mathrm{a})} \cdots \mathrm{B}_{(\mathrm{in} \mathrm{HB})}+\mathrm{HB}_{(\text {in HB })}$ 


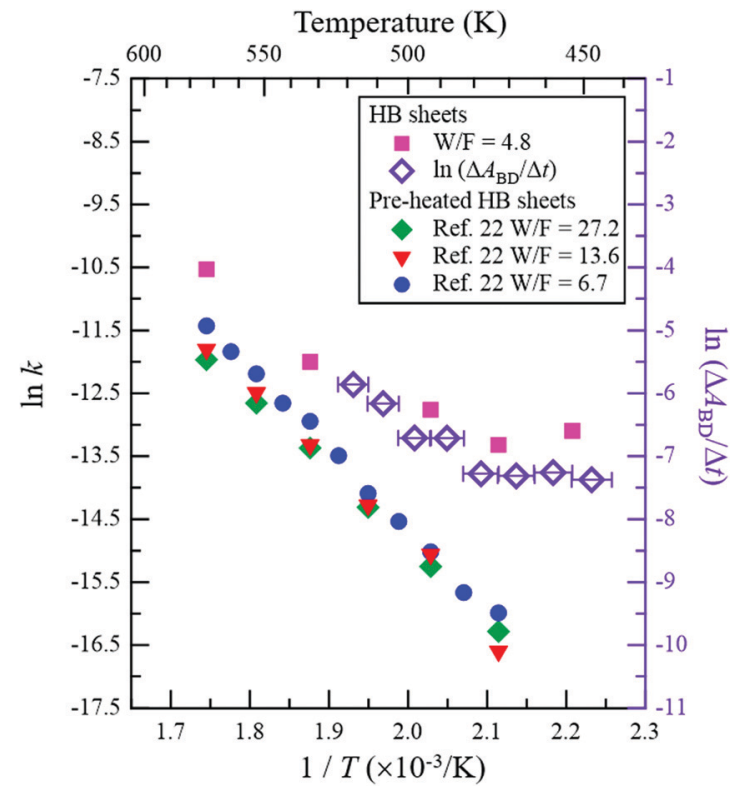

Fig. 5 Arrhenius plot of reaction rate $k$ (left axis). $k=\left(\mathrm{C}_{2} \mathrm{H}_{5} \mathrm{OH}\right.$ conversion [\%]])/100 $\times\left(\mathrm{C}_{2} \mathrm{H}_{5} \mathrm{OH}\right.$ flux [mol s$\left.\left.{ }^{-1}\right]\right) /(\mathrm{HB}$ amount [mol]) was estimated from the results shown in Fig. $2 \mathrm{e}\left(W / F=4.8 \mathrm{~g} \mathrm{~min} \mathrm{mmol}^{-1}\right) \cdot \ln \left(\Delta A_{\mathrm{BD}} / \Delta t\right)$ is plotted against $1 / T$ ( $T$ is the temperature) on the right axis to evaluate the formation rate of the $\mathrm{BD}$ bond, where $\Delta A_{\mathrm{BD}} / \Delta t$ is the time derivative of $\nu_{\mathrm{BD}}$ intensity $\left(A_{\mathrm{BD}}\right)$ for the data presented in Fig. 3 e. The Arrhenius plots for the $\mathrm{HB}$ sheets with heating pre-treatment (at $573 \mathrm{~K}$ under Ar flow for $1 \mathrm{~h}$ ) of the

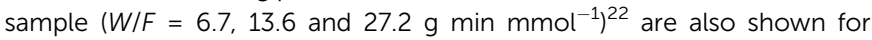
comparison (left axis).

$$
\mathrm{CD}_{3} \mathrm{CH}_{2} \mathrm{OH}_{(\mathrm{a})} \cdots \mathrm{B}_{(\mathrm{in} \mathrm{HB})}+\mathrm{H}_{(\mathrm{in} \mathrm{HB})} \rightarrow \mathrm{CD}_{3} \mathrm{CH}_{2}-\mathrm{B}_{(\mathrm{in} \mathrm{HB})}{ }^{\prime}+\mathrm{H}_{2} \mathrm{O}_{(\mathrm{g})}
$$

$$
\left.\mathrm{CD}_{3} \mathrm{CH}_{2}-\mathrm{B}_{(\mathrm{in} \mathrm{HB})}{ }^{\prime}+\mathrm{B}_{(\mathrm{in} \mathrm{HB})}\right)^{\prime \prime} \rightarrow{ }_{(\mathrm{RDS})} \mathrm{CD}_{2} \mathrm{CH}_{2(\mathrm{~g})}+\mathrm{D}-\mathrm{B}_{(\mathrm{in} \mathrm{HB})}{ }^{\prime \prime}
$$

where subscript (a) represents an adsorbate on the HB sheets, (g) represents the gas state, (RDS) represents the ratedetermining step, and $\mathrm{B}, \mathrm{B}^{\prime}$, and $\mathrm{B}^{\prime \prime}$ represent different $\mathrm{B}$ atoms in the HB sheets.

More specifically, at room temperature $(\sim 300 \mathrm{~K})$, ethanol vapor is adsorbed on the $\mathrm{HB}$ sheets under vacuum, which breaks some of the $\mathrm{BHB}$ bonds to form $\mathrm{BH}$ bonds as indicated by Fig. 1 (eqn (1) and Fig. 6bI). The adsorption structure of ethanol on the $\mathrm{HB}$ sheets is not clear, except for the local conversion of the structure from $\mathrm{BHB}$ to $\mathrm{BH}$ upon adsorption. Therefore, only one possible adsorption structure is shown in Fig. 6bI, which is assumed to be similar to the proposed adsorption structure of ethanol on H-ZSM5, in terms of the $\mathrm{H}-\mathrm{O}-\mathrm{H}$ configuration. ${ }^{47}$ Next, upon increasing the temperature, the $\mathrm{OH}$ group of ethanol may react with a hydrogen atom of the HB sheet, which results in the dehydration of ethanol and the formation of an ethyl group $\left(\mathrm{CD}_{3} \mathrm{CH}_{2}-\mathrm{B}_{(\mathrm{in} \mathrm{HB})}\right)$ as indicated in eqn (2) and Fig. 6bII, where $\mathrm{C}-\mathrm{O}$ bond cleavage and $\mathrm{C}-\mathrm{B}$ bond formation may occur as a concerted reaction. The reaction may be facilitated by tilting the molecular structure to promote contact between $\mathrm{C}$ and $\mathrm{B}$ (labeled 3 in Fig. $6 \mathrm{a}$ and bII). Meanwhile the bonds between the $\mathrm{O}$ and $\mathrm{H}$ atoms near the (a)

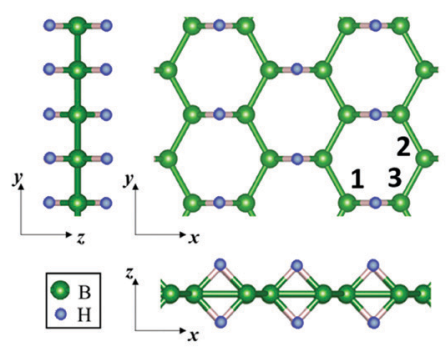

(b)
I. Adsorption

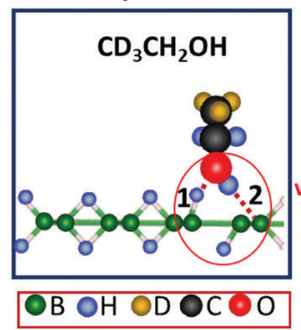

OB OH OD OCOO

III. Dehydrogenation

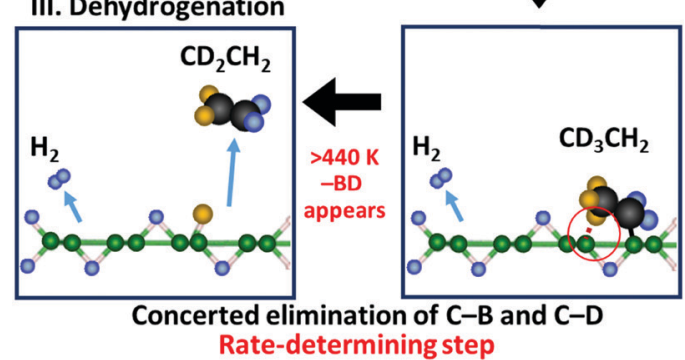

Fig. 6 Schematic reaction mechanism for ethanol dehydration on the $H B$ sheets. (a) HB model structure (note that the model structure shown here is the originally proposed local structure, ${ }^{17}$ whereas the real sample structure is not crystalline but amorphous and consists of a distorted hexagonal boron network structure with $\mathrm{BH}$ and $\mathrm{BHB}$ bonds ${ }^{19}$ ). (b) Schematic reaction mechanism for isotopically labelled ethanol $\left(\mathrm{CD}_{3} \mathrm{CH}_{2} \mathrm{OH}\right)$ dehydration on the $\mathrm{HB}$ sheets derived from the in situ FT-IR results. The adsorption structure of ethanol on the $\mathrm{HB}$ sheets is not clear, except for the local conversion of the structure from $\mathrm{BHB}$ to $\mathrm{BH}$ upon adsorption. Therefore, only one possible adsorption structure is shown in I.

B atoms (labeled 1 and 2 in Fig. 6a and bI) are retained, along with a distortion in the hexagonal boron network. This is merely a hypothesis regarding the possible structures, and further examination is required to ascertain the structural change. Meanwhile, hydrogen molecules are released by the partial decomposition of the HB sheets. Finally, as the rate-determining step, the hydrogen-deficient sites of $\mathrm{HB}$ (i.e., boron) abstract deuterium from the methyl group of $\mathrm{CD}_{3} \mathrm{CH}_{2}-\mathrm{B}_{(\text {in } \mathrm{HB})}$ in a dehydrogenation reaction, where the concerted elimination of $\mathrm{C}-\mathrm{B}$ and $\mathrm{C}-\mathrm{D}$ bonds occurs, and the desorption of $\mathrm{CD}_{2} \mathrm{CH}_{2}$ follows, as indicated by Fig. 2-5 (eqn (3) and Fig. 6bIII). The observed ethanol-ethylene conversion mechanism on the HB sheets is thus different from the so-called intramolecular dehydration reaction of ethanol. ${ }^{41}$ However, the mechanism may be similar to that in the case of the $\mathrm{H}$-form zeolite $\mathrm{er}^{28,42}$ in terms of the role of the Brønsted acidic sites and the mechanism of ethanol dehydration; the lattice oxygen 
and intermediate $\mathrm{C}_{2} \mathrm{H}_{5}-\mathrm{O}_{\text {(lattice) }}$ species in the case of the $\mathrm{H}$-form zeolite $^{28,42}$ correspond to the lattice boron and $\mathrm{C}_{2} \mathrm{H}_{5}-\mathrm{B}_{(\mathrm{in} \mathrm{HB})}$ species, respectively, in the case of the HB sheets.

\section{Conclusions}

We studied the conversion process of ethanol adsorbed on HB sheets during heating under vacuum through in situ FT-IR absorption spectroscopy with isotope labelling. Up to a temperature of $450 \mathrm{~K}$, the absorption band of $\mathrm{OH}$ in the ethanol adsorbed on HB disappeared, suggesting that the dehydration reaction may occur between the $\mathrm{OH}$ group of the adsorbed ethanol molecule and the hydrogen atom from the HB sheet. The decomposed ethanol then forms ethyl species on the HB sheets $\left(\mathrm{CH}_{3} \mathrm{CH}_{2}-\mathrm{B}_{(\mathrm{in} \mathrm{HB})}\right)$. Subsequently, in the rate-determining step, the dehydrogenation reaction forms a bond between the boron atom and a hydrogen atom from the methyl group of $\mathrm{CH}_{3} \mathrm{CH}_{2}-\mathrm{B}_{(\mathrm{in} \mathrm{HB})}$, rather than that of the methylene group, by a concerted elimination of the $\mathrm{C}-\mathrm{B}$ and $\mathrm{C}-\mathrm{H}$ bonds in $\mathrm{CH}_{3} \mathrm{CH}_{2}-\mathrm{B}_{\text {(in HB) }}$ above $440 \mathrm{~K}$. This is followed by the immediate desorption of the ethylene product. These results indicate that the ethanol dehydration process on HB involves the hydrogen atoms of the HB sheets. The obtained mechanistic insights are expected to aid the design of two-dimensional boroncontaining materials as effective catalysts for various reactions.

\section{Conflicts of interest}

There are no conflicts to declare.

\section{Acknowledgements}

This work was supported by JSPS Kakenhi (Grant No. 18K18989, 18H03874, 19H02551, and 19H05046:A01), the MEXT Element Strategy Initiative to Form Core Research Centre (JPMXP0112101001), the Ogasawara Foundation for the Promotion of Science \& Engineering, and MHI Innovation Accelerator LLC. We thank Prof. Takaki Kanbara for useful discussion.

\section{References}

1 Y. Wang, J. Mao, X. Meng, L. Yu, D. Deng and X. Bao, Chem. Rev., 2019, 119, 1806.

2 D. Deng, K. S. Novoselov, Q. Fu, N. Zheng, Z. Tian and X. Bao, Nat. Nanotechnol., 2016, 11, 218.

3 E. Antolini, Appl. Catal., B, 2012, 123-124, 52.

4 N. M. Julkapli and S. Bagheri, Int. J. Hydrogen Energy, 2015, 40, 948.

5 H. Wang, T. Maiyalagan and X. Wang, ACS Catal., 2012, 2, 781.

6 Y. Wang, Y. Shao, D. W. Matson, J. Li and Y. Lin, ACS Nano, 2010, 4, 1790.

7 I. Boustani, Surf. Sci., 1997, 370, 355.

8 E. S. Penev, S. Bhowmick, A. Sadrzadeh and B. I. Yakobson, Nano Lett., 2012, 12, 2441.
9 B. Mortazavi and T. Rabczuk, Energies, 2018, 11, 1573.

10 R. Zhang, Z. Li and J. Yang, J. Phys. Chem. Lett., 2017, 8, 4347.

11 F. M. Arnold, G. Seifert and J. Kunstmann, J. Phys. Commun., 2020, 4, 031001.

12 Y. Jiao, F. Ma, J. Bell, A. Bilic and A. Du, Angew. Chem., Int. Ed., 2016, 55, 10292.

13 T. A. Abtew, B. Shih, P. Dev, V. H. Crespi and P. Zhang, Phys. Rev. B: Condens. Matter Mater. Phys., 2011, 83, 094108.

14 Z. Zhu, X. Cai, C. Niu, C. Wang and Y. Jia, Appl. Phys. Lett., 2016, 109, 153107.

15 A. J. Mannix, B. Kiraly, M. C. Hersam and N. P. Guisinger, Nat. Rev. Chem., 2017, 1, 0014.

16 T. Kondo, Sci. Technol. Adv. Mater., 2017, 18, 780.

17 H. Nishino, T. Fujita, N. T. Cuong, S. Tominaka, M. Miyauchi, S. Iimura, A. Hirata, N. Umezawa, S. Okada, E. Nishibori, A. Fujino, T. Fujimori, S. Ito, J. Nakamura, H. Hosono and T. Kondo, J. Am. Chem. Soc., 2017, 139, 13761.

18 I. Tateishi, N. T. Cuong, C. A. S. Moura, M. Cameau, R. Ishibiki, A. Fujino, S. Okada, A. Yamamoto, M. Araki, S. Ito, S. Yamamoto, M. Niibe, T. Tokushima, D. E. Weibel, T. Kondo, M. Ogata and I. Matsuda, Phys. Rev. Mater., 2019, 3, 024004.

19 S. Tominaka, R. Ishibiki, A. Fujino, K. Kawakami, K. Ohara, T. Masuda, I. Matsuda, H. Hosono and T. Kondo, Chem, 2020, 6, 406.

20 S. Ito, T. Hirabayashi, R. Ishibiki, R. Kawamura, T. Goto, T. Fujita, A. Yamaguchi, H. Hosono, M. Miyauchi and T. Kondo, Chem. Lett., 2020, 49, 789.

21 R. Kawamura, N. T. Cuong, T. Fujita, R. Ishibiki, T. Hirabayashi, A. Yamaguchi, I. Matsuda, S. Okada, T. Kondo and M. Miyauchi, Nat. Commun., 2019, 10, 4880.

22 A. Fujino, S. Ito, T. Goto, R. Ishibiki, J. N. Kondo, T. Fujitani, J. Nakamura, H. Hosono and T. Kondo, ACS Omega, 2019, 4, 14100 .

23 D. N. Bakoyannakis, D. Zamboulis, G. A. Stalidis and E. A. Deliyanni, J. Chem. Technol. Biotechnol., 2001, 76, 1159.

24 M. A. Christiansen, G. Mpourmpakis and D. G. Vlachos, ACS Catal., 2013, 3, 1965.

25 Q. Pan, A. Ramanathan, W. Kirk Snavely, R. V. Chaudhari and B. Subramaniam, Top. Catal., 2014, 57, 1407.

26 F. Roca, L. De Mourgues and Y. Trambouze, J. Catal., 1969, 14, 107.

27 T. Maihom, P. Khongpracha, J. Sirijaraensre and J. Limtrakul, ChemPhysChem, 2013, 14, 101.

28 J. N. Kondo, H. Yamazaki, R. Osuga, T. Yokoi and T. Tatsumi, J. Phys. Chem. Lett., 2015, 6, 2243.

29 H. Nishino, T. Fujita, A. Yamamoto, T. Fujimori, A. Fujino, S. Ito, J. Nakamura, H. Hosono and T. Kondo, J. Phys. Chem. C, 2017, 121, 10587.

30 M. J. Frisch, G. W. Trucks, H. B. Schlegel, G. E. Scuseria, M. A. Robb, J. R. Cheeseman, G. Scalmani, V. Barone, G. A. Petersson, H. Nakatsuji, X. Li, M. Caricato, A. V. Marenich, J. Bloino, B. G. Janesko, R. Gomperts, B. Mennucci, H. P. Hratchian, J. V. Ortiz, A. F. Izmaylov, J. L. Sonnenberg, 
D. Williams-Young, F. Ding, F. Lipparini, F. Egidi, J. Goings, B. Peng, A. Petrone, T. Henderson, D. Ranasinghe, V. G. Zakrzewski, J. Gao, N. Rega, G. Zheng, W. Liang, M. Hada, M. Ehara, K. Toyota, R. Fukuda, J. Hasegawa, M. Ishida, T. Nakajima, Y. Honda, O. Kitao, H. Nakai, T. Vreven, K. Throssell, J. A. Montgomery, Jr., J. E. Peralta, F. Ogliaro, M. J. Bearpark, J. J. Heyd, E. N. Brothers, K. N. Kudin, V. N. Staroverov, T. A. Keith, R. Kobayashi, J. Normand, K. Raghavachari, A. P. Rendell, J. C. Burant, S. S. Iyengar, J. Tomasi, M. Cossi, J. M. Millam, M. Klene, C. Adamo, R. Cammi, J. W. Ochterski, R. L. Martin, K. Morokuma, O. Farkas, J. B. Foresman and D. J. Fox, Gaussian 16, Gaussian, Inc., Wallingford CT, 2016.

31 J.-P. Perchard and M.-L. Josien, J. Chim. Phys. Phys.-Chim. Biol., 1968, 65, 1834.

32 J.-P. Perchard and M.-L. Josien, J. Chim. Phys. Phys.-Chim. Biol., 1968, 65, 1856.

33 J. Eng, Jr., K. Raghavachari, L. M. Struck, Y. J. Chabal, B. E. Bent, G. W. Flynn, S. B. Christman, E. E. Chaban, G. P. Williams, K. Radermacher and S. Mantl, J. Chem. Phys., 1997, 106, 9889.

34 D. J. Burke, A. J. Wolff, J. L. Edridge and W. A. Brown, J. Chem. Phys., 2008, 128, 104702.
35 N. Boudin, W. A. Schutte and J. M. Greenberg, Astron. Astrophys., 1998, 331, 749.

36 S. C. Street and A. J. Gellman, Colloids Surf., 1995, 105, 27.

37 A. J. Barnes and H. E. Hallam, Trans. Faraday Soc., 1970, 66, 1932.

38 J. Xu, X. Zhang, R. Zenobi, J. Yoshinobu, Z. Xu and J. T. Yates, Jr., Surf. Sci., 1991, 256, 288.

39 Y. Yu, K. Lin, X. Zhou, H. Wang, S. Liu and X. Ma, J. Phys. Chem. C, 2007, 111, 8971.

40 L. Wang, T. Ishiyama and A. Morita, J. Phys. Chem. A, 2017, 121, 6701.

41 M. Zhang and Y. Yu, Ind. Eng. Chem. Res., 2013, 52, 9505.

42 J. N. Kondo, K. Ito, E. Yoda, F. Wakabayashi and K. Domen, J. Phys. Chem. B, 2005, 109, 10969.

43 S. Roy, G. Mpourmpakis, D. Hong, D. G. Vlachos, A. Bhan and R. J. Gorte, ACS Catal., 2012, 2, 1846.

44 J. F. DeWilde, H. Chiang, D. A. Hickman, C. R. Ho and A. Bhan, ACS Catal., 2013, 3, 798.

45 J. F. DeWilde, C. J. Czopinski and A. Bhan, ACS Catal., 2014, 4, 4425 .

46 K. Alexopoulos, M. John, K. Van der Borght, V. Galvita, M. Reyniers and G. B. Marin, J. Catal., 2016, 339, 173.

47 F. Haase and J. Sauer, J. Am. Chem. Soc., 1995, 117, 3780. 